\title{
Social Media Usage for Learning English Language
}

DOI: https://doi.org/10.47175/rielsj.v2i3.289

\author{
| Saidatul Hanim | \\ Universitas Prima Indonesia, \\ Indonesia \\ saidatulhanim@unprimdn.ac.id
}

\begin{abstract}
The reason of this consider was to decide the sorts of social media utilized by fourth-semester students of the Department of English Literature, Universitas Negeri Medan, for learning English. The analyst utilized clear subjective inquire about, and the information were collected using a questionnaire. The participants were 50 students of the Department of English Letters, Muria Kudus University. The results showed that the social media used by students to learn English were YouTube (94\%), Instagram (72\%), WhatsApp (62\%), Twitter (32), Facebook (30\%), Line (10\%), Google (2\%), TikTok (2\%).

KEYWORDS

English Language Learning; learning english; social media
\end{abstract}

\section{INTRODUCTION}

Social media can be characterized as web and versatile based advances which are broadly utilized for communication purposes. It may be a set of Web 2.0 e-platforms utilized for socializing chatter, sharing data. Social media comprises of exercises that include socializing and organizing online through words, pictures, and recordings. You Tube, TikTok, and Instagram are for the most part common social media stages known to the open. This stage gives clients with numerous exercises for interaction between individuals, where everybody can share, trade, comment, talk about, and make data and information collaboratively. Utilizing social media, individuals can make individual pages and interface with companions to share substance. For that reason, social media has been famously utilized by individuals over the last few years (Boyd: 2014)

The notoriety of social media includes a tremendous affect on understudies. Understudies spend more of their time utilizing social media through their tablets or portable phones. Understudies indeed have accounts that they oversee themselves to associated with companions and indeed to do social interaction with new individuals all over the world. Hence, this may be adjusted by instructors or teachers to create certain exercises that utilize social media in dialect learning. Instructors or teachers can effectively utilize Instagram to remain associated with understudies (Zhang, 2013).

There are four main purposes for using social media applications, namely: entertainment, socialization, informative and academic (Yang, 2020). The result of educators' practice of introducing social media applications into contextual language teaching and learning to improve learners' language proficiency, "academic" is gradually becoming a factor. Take for example Tik Tok, language learning videos ranked second most among popular knowledge sharing videos in 2019. In fact, massive research has explored the effects of Use of social networks to support language apprentices. to improve their language skills and knowledge. However, limited research has examined the feasibility of using Tik Tok to learn English pronunciation.

Agreeing to Harmer (2001) emphasizes that the most point of instructing and learning in any dialect is to enable students to communicate within the target dialect and in the event that this can be the case, communication is an vital term to clarify. Communication means 
understanding and being caught on. Harmer (2001) too emphasizes that through articulation instruction, understudies don't as it were learn distinctive sounds and voice highlights but too make strides their talking abilities. Concentrating on sounds causes learners to realize where words got to be emphasized and they donate them more data almost talked English and offer assistance them gain understanding and clarity goals.

Based on this description, this research focuses on what social media are most often used as learning media that can improve students' English skills?

\section{LITERATURE REVIEW}

\section{Social Media}

Andreas Kaplan and Michael Haenlein states social media as "a bunch of Internet-based applications that build on the ideological and innovative facilities of Web 2.0 and enable creation and commerce. of user-generated substance" (Kaplan, Andreas M.; Michael Haenlein (2010) "Clients of the world, join together! The challenges and openings of Social Media". Business Horizons 53(1): 59-68).

Agreeing to Van Dijk (2013) social media may be a media stage that centers on the presence of clients who encourage them in their exercises and collaboration. Social networks can be seen as an Internet medium (facilitator) that strengthens the relationship between customers, as well as a social bond. In expansion, Boyd (2009) clarifies that social media can be translated as a collection of program that permits people.

\section{Social Media Function}

Indrajit (2004) also revealed that the functions of information technology in education include: 1) like a knowledge store; 2) as a learning aid; 3) as educational facilities; 4) as a standard of competence; 5) as administrative support; 6) as a management tool; 7) as educational infrastructure.

Rosenberg (in Widiasworo, 2019:50) that the development of advances in information technology, the shift from conventional learning to modern learning has a positive impact. Thus, it can be concluded that the use of learning media including digital social media will be able to add alternatives in improving understanding and become an alternative source of knowledge that can support the success of the teaching process in the classroom.

\section{Social Media Sample \\ Youtube}

YouTube could be a site for sharing recordings or observing recordings shared by different parties. YouTube was first founded in February 2005 and is headquartered in San Bruno, California, United States. YouTube can be accessed for free with an internet connection. Budiargo (2015: 47) says YouTube is a web video, and its fundamental utilize is as a medium for looking, seeing and sharing unique recordings to and from all corners of the world by means of a web. YouTube is known by the slogan: Broadcast Yourself, which could be a video sharing location that gives different varying media data.

Among the existing educational media, internet media is the media that is trending nowadays. Easy, fast and free access makes YouTube grow not only as a source of entertainment, but also as a medium for business and educational purposes. YouTube is considered and able to provide updated and practical information. Budiargo (2015) says that the main use of YouTube is as a medium for searching, See and share original videos from and to all corners of the world through a web.In addition, Purwanti (2015) believes that media with video is clearly more likely to be easy to remember and understand lessons 
because it does not use one sense. Burnett and Melissa (Wijanarko, 2017) also said that the use of interactive videos such as YouTube into the learning process would improve students' skills. According to Ratna (2013) as a Learning Media YouTube has several advantages, namely:

\section{a. Potential}

YouTube is the foremost well-known location on the web today that's able to supply alter esteem to instruction.

b. Practical

YouTube is simple to utilize and can be taken after by all bunches counting understudies and teachers.

c. Informative

YouTube gives data around the improvement of instruction, innovation, etc.

d. Intelligently

YouTube encourages us to talk about or inquire questions and indeed audit a learning video.

e. Shareable

YouTube has HTML link facilities, Embed learning video code that can be shared on social networks such as Facebook, Twitter and blogs/websites.

f. There is TeacherTube

There is another alternative that is part of YouTube, namely TeacherTube. In 2007, TeacherTube was launched, an online teacher community to post and view videos made by educators.

\section{TikTok}

TikTok is one of the foremost well known apps within the world: hundreds of millions of clients, numerous of them children and high schoolers, utilize it to transfer, observe, and browse lip adjust recordings and memes. TikTok, created by ByteDance, a Chinese company, permits clients to transfer lip-sync recordings of up to 60 seconds with different inventive and intelligently highlights. It is the speediest developing app and ranks as the seventh most downloaded app within the final decade.

Tik Tok Application as a Media for Learning English Skills

a. Listening Skills

Concurring to Arono in (Loren, 2017) "Intuitively interactive media is an compelling learning media to make strides basic tuning in abilities for understudies. Learning media as one of the components in learning plays an vital part so that learning can take put in agreement with the learning goals. Starting from this opinion, it can be seen that the learning media needed is audio-visual to help listening learning. In accordance with the features offered, the Tik Tok application can accommodate the character's audio-visual needs.

b. Speaking Skills

Speaking is the skill of pronouncing articulation sounds or words that express, state or convey intentions, ideas, ideas, thoughts, and feelings that are arranged and developed according to the needs of the listener so that what is conveyed can be reached (Wahyuni Oktavia \& Kunci, 2015). The method of passing on thoughts, thoughts, or eagerly by talking for each person is diverse. Subsequently, learning media must be outlined fittingly in arrange to move forward by and large talking abilities. The Tik Tok application gives its users the ease and flexibility to insert background sounds into the application. With these features, the Tik Tok application 
processes words that express, express or convey intentions, ideas, ideas, thoughts, and feelings that are compiled and developed according to the needs of the listener.

c. Writing skills

Writing skills are a person's way of putting ideas or ideas into writing so that others can understand and understand the information contained in it (Aji, 2016). The importance of writing skills is so important that writing skills are one of the language skills that get attention in language teaching, especially Indonesian. The quality of the process and results of writing skills, is determined by the teacher's role as a designer of learning in the classroom.

d. Reading Skills

Reading is a skill that must be mastered by everyone in addition to the other three language skills. "Perusing has two purposes: perusing for joy and perusing to carry data. Perusing for delight centers on the coordinate involvement of perusing. They concentrate on the considerations, pictures, sentiments, and affiliations produced amid perusing. Perusing to communicate data concentrates on open, common references to words and images within the text." Tomkins and Hoskisson in (Darmawan, 2013). Based on the purpose of reading into two, reading for recreational purposes and reading for information gathering purposes. This is because reading is a means to learn the other world that is desired so that humans can expand knowledge, and contain written messages in reading material. however, reading is an easy job. Reading is a process that is developed by using techniques that are suitable for the purpose of reading. (Syifa, 2013)

\section{Instagram}

Actually, Instagram may be a portmanteau of moment camera and wire. These two words blend the sound and incorporate the meaning into Instagram. Instagram may be a parcel of fun and clients can easily share their life with their companions through a arrangement of pictures. Instagram could be a generally unused frame of communication where clients can effortlessly share their upgrades by taking photographs or recordings (Yuheng $\mathrm{Hu}, 2014$ ).

For presently, Instagram can take on numerous capacities: make an account, post substance (15 seconds picture or video), apply channels, include content, tag clients, include areas, and investigate (seek for) hashtags/users (Ali:2014).

\section{Share Photos and Videos}

Instagram allows clients to require pictures or recordings utilizing the application, or clients can also share photos/videos as of now within the user's camera album. In expansion, clients can include depictions within the shape of words, sentences or sections in their photos/videos. The portrayal itself can give data approximately what really happened in connection with the uploaded photo/video. If used in language learning, uploading features and pictures/videos are very relevant to help language learners learn how to write effectively in the language. In other words, Instagram is useful to help students learn writing.

\section{Social Networks}

Instagram, like other social networks, is a depiction of social life like having friends or being called followers on Instagram. On Instagram, users can make friends with other people who 'follow' them. Through this feature, users can interact with other people, users can also press the 'love' icon and leave comments to other users. In addition, users can also communicate using the direct message feature. 


\section{RESEARCH METHODS}

This investigate employments a expressive subjective investigate strategy. As a strategy, substance investigation is interesting in that has both a quantitative (Krippendorff, 2004; Neuendorf, 2002) and a subjective (Berg, 2001; Burnard, 1991; Catanzaro, 1988; DowneWambolt, 1992) strategy and can be used inductively or deductively. Quantitative substance investigation has its root in media investigate, whereas subjective substance investigation has its roots initially in social inquire about. In quantitative substance examination, actualities from the content are displayed within the shape of recurrence In subjective substance examination, information are displayed in words and subjects, which makes it conceivable to draw a few translation of the comes about a subject.

Participants in this study consisted of 50 semester IV students of the Department of English Literature, Universitas Negeri Medan, for the 2019/2020 academic year. To collect data, the researcher used a questionnaire.

Data collection is carried out as the following steps:

1. Prepare a questionnaire sheet.

2. The distribution of questionnaires.

3. Ask students to answer the questionnaire sheet.

4. Collect questionnaire sheets

5. Read and study the questionnaires filled out by students.

6. Categorize the answers to the questionnaire into percentages.

\section{RESULTS AND DISCUSSION}

After analyzing the 50 reactions from fourth semester understudies of English Writing Division of Universitas Negeri Medan, the sorts and rate of the social media utilized by understudies are displayed within the taking after table.

Table 1. The Kinds and Percentage of Social Media to Learn English

\begin{tabular}{l|ll}
\hline No & Kinds of Social Media & Frequency \\
\hline 1 & YouTube & $94 \%$ \\
2 & Instagram & $72 \%$ \\
3 & WhatsApp & $62 \%$ \\
4 & Twitter & $32 \%$ \\
5 & Facebook & $30 \%$ \\
6 & Line & $10 \%$ \\
7 & Google & $2 \%$ \\
8 & TikTok & $2 \%$ \\
\hline
\end{tabular}

The researcher points out that the overwhelming social network that students use is YouTube. It seems like the rate $(94 \%)$. This means that YouTube is the main social medium that students use to learn English. It is because YouTube offers numerous recordings to learn English. This makes it easier for students to memorize recordings in English when watching videos on YouTube.

The second is Instagram at a rate $(72 \%)$. Instagram could be a popular social medium. Interestingly, there are assets. There are recordings, captions, photos and other things. Because of this, students can share their own on Instagram. By a percentage (62\%), WhatsApp is the third best option among students, and students can share their thoughts with their peers and easily communicate about learning English. At this point, Twitter was at a rate $(32 \%)$. Twitter broadcasts curious tweets that students can learn and improve their 
English skills. It is followed by Facebook with the rate $(30 \%)$ in the fifth line with the percentage $(10 \%)$.

The other social networks that students use to learn English are the following: Google (2\%), TikTok $(2 \%)$.

\section{CONCLUSION}

The result seems that there are numerous types of social networks that students use to memorize English. The social networks that the students use are YouTube, Instagram, WhatsApp, Twitter, Facebook and Line. Students also use other social networks to memorize English. There are Google and TikTok.

Based on the conclusion over, a few recommendations are proposed as takes after. To begin with, the data around the sorts of social media that the fourth semester understudies of English Writing Office of Universitas Negeri Medan use for learning English ought to be utilized to assist the teachers oversee their instructing and learning process. The speakers can utilize social media as a learning instrument to assist understudies create their English dialect aptitudes. Another, the understudies ought to attempt and utilize others social media proficiently for learning English. The analysts suggest encourage analysts to conduct comparable investigate by investigating the other perspectives of utilizing social media in Learning English.

\section{REFERENCES}

Li, V. (2017). Social media in English language teaching and learning. International Journal of Learning and Teaching, 3(2), 148-153.

Dhanya, G. (2016). Influence of social media on English language learning. Journal of English Language and Literature (JOELL), 3(1), 105-110.

Hamadeh, W., Bahous, R., Diab, R., \& Nabhani, M. (2020). Using Social Media to Enhance Second Language Learning. Computer-Assisted Language Learning Electronic Journal, 21(2), 132-149.

Handayani, F. (2015). Instagram as a teaching tool? Really?. Proceedings of ISELT FBS Universitas Negeri Padang, 4(1), 320-327.

Pratiwi, A. E., Ufairah, N. N., \& Sopiah, R. S. (2021, March). Utilizing Tiktok Application As Media for Learning English Pronunciation. In International Conference on Education of Suryakancana (IConnects Proceedings).

Wang, H. C., \& Chen, C. W. Y. (2020). Learning English from YouTubers: English L2 learners' self-regulated language learning on YouTube. Innovation in Language Learning and Teaching, 14(4), 333-346.

Jones, T., \& Cuthrell, K. (2011). YouTube: Educational potentials and pitfalls. Computers in the Schools, 28(1), 75-85. 